\title{
Estratégias para o enfrentamento do absenteísmo em consultas odontológicas nas Unidades de Saúde da Família de um município de grande porte: uma pesquisa-ação
}

\author{
Strategies for tackling absenteeism in dental appointments \\ in the Family Health Units of a large municipality: action research
}

Claudia Ângela Gonçalves ${ }^{1}$

Fabiana de Lima Vazquez ${ }^{1}$

Glaucia Maria Bovi Ambrosano ${ }^{1}$

Fábio Luiz Mialhe ${ }^{1}$

Antonio Carlos Pereira ${ }^{1}$

Karin Luciana Migliato Sarracini ${ }^{1}$

Luciane Miranda Guerra ${ }^{1}$

Karine Laura Cortellazzi ${ }^{1}$

${ }^{1}$ Departamento de Odontologia Social, Faculdade de Odontologia de Piracicaba, Unicamp. Av. Limeira 901, Vila Rezende. 13414-903 Piracicaba SP Brasil. apereira@fop.unicamp.br

\begin{abstract}
The aim of this study was to analyze the reasons for missed appointments in dental Family Health Units (FHU) and implement strategies to reduce same through action research. This is a study conducted in 12 FHUs in Piracicaba in the State of São Paulo from January, 1 to December, 31 2010. The sample was composed of 385 users of these health units who were interviewed over the phone and asked about the reasons for missing dental appointments, as well as 12 dentists and 12 nurses. Two workshops were staged with professionals: the first to assess the data collected in interviews and develop strategy, and the second for evaluation after 4 months. The primary cause for missed appointments was the opening hours of the units coinciding with the work schedule of the users. Among the strategies suggested were lectures on oral health, ongoing education in team meetings, training of Community Health Agents, participation in therapeutic groups and partnerships between Oral Health Teams and the social infrastructure of the community. The adoption of the single medical record was the strategy proposed by professionals. The strategies implemented led to a $66.6 \%$ reduction in missed appointments by the units and the motivating nature of the workshops elicited critical reflection to redirect health practices.
\end{abstract}

Key words Family Health, Absenteeism, Primary health care, Oral health
Resumo $O$ objetivo deste trabalho foi analisar os motivos das faltas às consultas odontológicas em Unidades de Saúde da Família (USF) e implementar estratégias para sua redução por meio da pesquisa-ação. $O$ estudo foi realizado em 12 USF de Piracicaba/SP, de 01 de janeiro a 31 de dezembro de 2010. A amostra se consistiu de 385 usuários, entrevistados por telefone, sobre os motivos das faltas, além de 12 cirurgiões-dentistas e 12 enfermeiras. Realizaram-se duas oficinas com os profissionais: uma para problematização dos dados coletados nas entrevistas e elaboração de estratégias; e outra após 4 meses, para avaliação. O maior motivo de faltas foi a coincidência do horário de funcionamento das unidades com o de trabalho dos usuários. Dentre as estratégias ressaltou-se a realização de palestras sobre saúde bucal, educação permanente nas reuniões de equipe, capacitação dos Agentes Comunitários de Saúde, participação em grupos terapêuticos e parcerias entre Equipe de Saúde Bucal e equipamentos sociais da comunidade. A adoção de prontuário único foi a estratégia desafiadora encontrada pelos profissionais. Concluiu-se que as estratégias implementadas levaram à diminuição das faltas em 66,6\% e o caráter motivador das oficinas possibilitou a reflexão crítica para o redirecionamento da prática em saúde.

Palavras-chave Saúde da Família, Absenteísmo, Atenção Primária à Saúde, Saúde bucal 


\section{Introdução}

O paradigma que orienta o modelo de atenção a saúde vigente no Brasil vem sofrendo grandes mudanças nas últimas décadas no sentido da valorização das ações de promoção e proteção da saúde, prevenção das doenças e atenção integral às pessoas. Tais pressupostos são capazes de impactar positivamente o novo modelo, superando as práticas curativistas e a fragmentação do cuidado a saúde ${ }^{1}$.

Nessa perspectiva, o modelo de Saúde da Família apresentou-se, então, como estratégia reorientadora do processo de trabalho ${ }^{2}$, já que trouxe como proposta a compreensão do ser humano em sua dimensão biológica, agregada às influências psicológicas, sociais e culturais, marcantes do meio onde o sujeito está inserido ${ }^{3}$.

Em relação à saúde bucal, os modelos de atenção excludentes, vigentes no Brasil até o final do século XX, impactaram negativamente nos indicadores de acesso e epidemiológicos. A baixa cobertura em saúde bucal originou uma geração de desassistidos.

Dessa forma, a inserção da saúde bucal na estratégia de saúde da família em 2002 trouxe a perspectiva e a proposta de uma nova forma de atuação, tendo como foco a família - seu principal eixo de trabalho - e consolidando um novo modelo de atenção ${ }^{4}$.

O cenário de exclusão e os indicadores epidemiológicos desfavoráveis, que caracterizaram historicamente a saúde bucal no Brasil, trouxeram como consequência desconfiança na resolutividade do sistema por parte dos usuários, o que, ainda hoje se traduz em problemas de adesão dos mesmos ao sistema.

Isso se configura numa causa de absenteísmo no SUS, traduzido, do ponto de vista gerencial, como "ociosidade da capacidade instalada".

A ausência do usuário agendado no serviço traduz-se por perda de recursos públicos. Contudo, os prejuízos na continuidade da assistência e na resolubilidade das demandas de saúde são também impactantes ${ }^{6}$. Além disso, ressalta-se, como consequências dessas faltas, o aumento na fila de espera e das demandas por urgência.

Os obstáculos ou barreiras de acesso aos serviços foram associados ao absenteísmo em serviços de saúde em vários estudos ${ }^{5,7}$.

Nesse sentido, categorizaram-se as barreiras ao atendimento odontológico em três classes: as relacionadas ao indivíduo (baixa percepção de necessidade; ansiedade e medo; custos; e dificuldade de acesso); as da prática da profissão (inadequação dos recursos humanos; distribuição geográfica desigual; formação inapropriada às novas necessidades e demandas da população; e sensibilidade insuficiente para as necessidades do paciente), aquelas relativas à sociedade (número insuficiente de ações de promoção de saúde; instalações impróprias dos serviços; e reduzido auxílio financeiro à pesquisa $)^{8}$.

Percebe-se, portanto, a importância estrutural e organizacional dos serviços aliado ao aspecto relacional que envolve a prática odontológica (como todas as demais práticas em saúde).

A despeito das mudanças de paradigma propostas pela estratégia de saúde da família, suas estruturas continuam permeáveis ao modelo hegemônico; isso corrompe o processo de trabalho cotidiano, apontando para a necessidade de construção de práticas de saúde mais solidárias, acolhedoras e consequentemente mais resolutivas?.

Torna-se importante, então, a utilização das tecnologias leves - de relações - dentro da produção dos atos em saúde, com a consequente valorização de dispositivos como o vínculo e o acolhimento. Observa-se, no campo do trabalho em saúde, características particulares, já que se lida diretamente com subjetividades. Assim, toda ação assistencial de um profissional de saúde junto a um usuário é realizada através de um trabalho vivo em ato, por meio do qual há o encontro de duas pessoas, atuando uma sobre a outra em um processo relacional ${ }^{10}$.

A prática e o cuidado à saúde podem e devem ser atividades - fim e primordiais. Desta forma envolve uma variedade de aspectos a se considerar: o da arte, que trata da criatividade e da estética na saúde, o ético, que envolve respeito, compreensão entre os atores sociais envolvidos, e o da ciência, que trata do conhecimento e da pesquisa necessários às intervenções em saúde ${ }^{11}$.

Contudo, há que se problematizar o autocuidado na mesma perspectiva do cuidado; além disso, levar-se em conta a complexidade da realidade local como complicadora das práticas de autocuidado, aqui entendido como algo além da simples adesão ao tratamento prescrito.

Pensar a não adesão na perspectiva do autocuidado e não como falta de compromisso com a saúde possibilita reconhecer o usuário como um aliado na luta pela promoção de saúde nas comunidades. Por outro lado, implica também em repensar a forma como o mesmo tem sido abordado em suas necessidades de saúde, para que haja a possibilidade de corresponsabilização pelos cuidados ${ }^{12}$.

Nessa perspectiva, o reconhecimento, por parte dos profissionais, da complexidade da re- 
lação dentista-paciente promove melhor aceitação e adesão ao tratamento e, consequentemente, maior possibilidade de sucesso, não só para quem presta, mas também para quem recebe os cuidados $^{13}$.

Para a construção de uma prática clínica ampliada e centrada no usuário, onde desafios como a adesão e a confiança do usuário sejam conquistados, é necessária ampla reflexão crítica, tanto de relações, quanto de processos de trabalho. Além disso, requer a construção de estratégias e caminhos para a superação dos desafios, que sejam propostas e construídas pelos atores e em consonância os cenários particulares de atuação.

Nesse sentido, a pesquisa-ação, apresenta-se com uma proposta metodológica muito oportuna, já que assume o caráter emancipatório, pois mediante a participação consciente, os sujeitos da pesquisa passam a ter oportunidade de se libertar de mitos e preconceitos que organizam suas defesas à mudança, e assim reorganizam a sua autoconcepção de sujeitos históricos. Além disso, apresenta flexibilidade metodológica como um de seus componentes essenciais ${ }^{14}$.

Assim, esse trabalho objetivou analisar os motivos que levaram os usuários a faltar às consultas odontológicas na Estratégia de Saúde da Família no município de Piracicaba/SP e implementar estratégias junto aos profissionais de saúde, por meio da pesquisa-ação, para o enfrentamento do absenteísmo.

\section{Métodos}

Trata-se de um estudo de pesquisa-ação, realizado no município de Piracicaba - SP e aprovado pelo Comitê de Ética em Pesquisa da FOP-UNICAMP.

O nível primário de atenção à Saúde do município de Piracicaba (SP), cenário desse estudo, é composto de 34 Unidades de Saúde da Família e 23 Unidades Básicas de Saúde.

A atenção em saúde bucal no município é composta por: 13 Equipes de Saúde Bucal módulo I (cirurgião-dentista e auxiliar de saúde bucal) inseridas nas Equipes de Saúde da Família (médico, enfermeiro, técnico ou auxiliar de enfermagem e agentes comunitários de saúde), 17 equipes em Unidades Básicas de Saúde (cirurgião-dentista e auxiliar de saúde bucal) e por 02 Centros de Especialidades Odontológicas (CEO), que atendem as especialidades de endodontia, periodontia, cirurgia buco-maxilo, odontopediatria, dentística, pacientes especiais e atendimento de bebês de 0 a 4 anos.
Esta pesquisa foi realizada nas 12 Unidades de Saúde da Família do município de Piracicaba/ SP, que contemplavam Equipes de Saúde Bucal no ano de 2010.

Embora o presente estudo, por ser pesquisa -ação, não necessitasse de amostra representativa, ainda assim considerou-se uma amostra de usuários de cada Unidade de Saúde, a fim de se obter elementos que traduzissem cada um desses cenários, para embasar as discussões posteriores. Para tanto, calculou-se um número amostral de 385 entrevistas aos usuários, aleatorizados a partir da lista de contato telefônico. Foi considerando um nível de confiança de 95\%, erro amostral de 5\%, tomando como critério de cálculo a proporção de 0,50 (50\% de mesma resposta a quaisquer das perguntas). Assim, os entrevistados foram selecionados de forma proporcional e aleatória nas Unidades de Saúde participantes.

Os demais atores desse estudo foram os 12 cirurgiões-dentistas e os 12 enfermeiros das referidas Unidades.

Foram excluídos indivíduos que não mais residiam no território adstrito à USF e/ou não informaram telefone para contato ou, ainda, que não aceitaram participar da pesquisa.

Mediante as listagens obtidas em cada USF, a pesquisadora realizou contato telefônico com os usuários, que responderam às questões:

1- Você estava em tratamento odontológico na USF em 2010?

2- Qual o motivo de ter faltado à consulta odontológica?

3- Você possui convênio odontológico?

4- Você estuda ou trabalha?

5- Você cuida de alguém? (filhos, acamados, impossibilitados, etc.)

Os indivíduos foram contatados de modo aleatório, seguindo-se as listagens obtidas. Para os casos de insucesso no contato com determinado paciente, outro imediatamente posterior na listagem foi entrevistado, até a obtenção do número estabelecido para a Unidade.

Buscando-se identificar o perfil dos profissionais e sua percepção sobre os motivos das faltas dos usuários às consultas foi aplicado um questionário aos 12 cirurgiões-dentistas, o qual solicitava as informações: nome; idade; ano de conclusão do curso de Odontologia; se possui pósgraduação e qual; em qual USF (Unidade de Saúde da Família) atua e há quanto tempo; se já participou de algum curso de capacitação sobre Estratégia de Saúde da Família (ESF); qual a conduta aplicada a pacientes que faltam à consulta odontológica; opinião sobre qual(is) o(s) motivo(s) das faltas 
dos pacientes às consultas odontológicas; quais as estratégias propostas pela Equipe de Saúde Bucal/ Equipe de Saúde da Família para diminuir as faltas dos pacientes às consultas?

Segundo protocolo da Coordenação de Saúde Bucal do município, em caso de falta sem justificativa pelo usuário, o mesmo perde a vaga, devendo retornar ao tratamento ou à consulta em um próximo agendamento da USF. Para os casos de uma falta justificada, há reagendamento.

\section{Oficinas de pesquisa-ação}

Foi utilizada a tipologia da ação pesquisa diagnóstica ${ }^{15}$.

Após as entrevistas foi aplicada a metodologia da pesquisa-ação aos cirurgiões-dentistas e enfermeiras de cada USF, mediante a realização de 02 oficinas, coordenadas pela pesquisadora, orientadora e coorientadora, utilizando-se, para tal, de metodologias ativas e problematizadoras.

\section{Primeira oficina}

A primeira oficina aconteceu na FOP/UNICAMP. Participaram 22 profissionais, entre cirurgiões-dentistas e enfermeiras pertencentes às 12 USF, além da Coordenadora em Saúde Bucal do município. Somente uma USF não teve representatividade nesta oficina, já que nenhum profissional compareceu ao evento.

Após uma breve apresentação sobre o impacto das faltas no serviço com demonstração de dados quantitativos, os participantes foram divididos em 03 grupos, compostos por Unidades segundo sua localização em áreas de maior ou menor exclusão social.

Após discussão, cada grupo elencou sua percepção sobre os motivos das faltas dos usuários às consultas odontológicas, anotando semelhanças e diferenças entre as Unidades. O produto de tal discussão foi apresentado em plenária. Foi, então, apresentada, pela pesquisadora, a percepção dos pacientes sobre os motivos das faltas.

Em seguida, os grupos reuniram-se novamente a fim de propor estratégias para diminuição das faltas às consultas, apresentando-as individualmente em plenária, o que ensejou a plenária final, onde, por fim, foram pactuadas, coletivamente, tais estratégias, originando um relatório final - posteriormente encaminhado às USF - com as estratégias propostas:

Às equipes:

1- Maior integração entre os profissionais da USF (parcerias entre médicos/ equipe de enferma- gem/ equipe de saúde bucal e ACS), possibilitando a formação de uma equipe coesa, motivada e direcionada a objetivos comuns;

2- Adoção de Prontuário Único nas Unidades a fim de fortalecer o vínculo entre os profissionais da equipe;

3- Educação continuada durante as reuniões de equipe, com a participação do cirurgião-dentista (CD) expondo temas de Odontologia, buscando a valorização/importância da saúde bucal dentro da equipe;

4- Capacitação dos ACS em saúde bucal, a ser desenvolvida pelo cirurgião-dentista;

5- Participação da equipe de saúde bucal em todos os grupos da USF (gestantes, hipertensos, diabéticos, grupo do leite, etc.) para maior vínculo com a comunidade;

6- Agendamento de consulta odontológica para a gestante na abertura do Sistema de Informação de Pré-natal (SIS/Pré-natal);

7- Parcerias entre equipe de saúde bucal/escolas/creches para atendimento das crianças após autorização do responsável;

8- Parcerias em rede: participação da equipe de saúde bucal em Comissão Local de Saúde ou em outros espaços sociais do território;

9- Ampliação do acesso dos trabalhadores às consultas, agendando em horário mais conveniente conforme o trabalho do paciente (sugestão: marcar no primeiro ou último horário do período ou realizar o tratamento nas férias do empregado);

10- Promoção de atividades lúdicas para pacientes temerosos ao tratamento odontológico;

11- Promoção de atividades vinculadas de acordo com a realidade local, como por exemplo, avaliação odontológica na vacinação aos 5 anos da criança.

Aos gestores:

1- Educação permanente a todas as equipes, através de cursos e capacitações ofertados pela Secretaria de Saúde;

2- Curso Introdutório em Saúde da Família e SUS para todos os profissionais das equipes;

3- Aumento da oferta de procedimentos odontológicos de maior complexidade na rede como próteses parciais, unitárias, endodontia de molares sem restrição por idade, ortodontia preventiva.

\section{Segunda oficina}

Após 04 meses, no mesmo local, as equipes reuniram-se novamente para avaliação da implantação das estratégias estabelecidas na primeira oficina. Participaram da mesma, 19 profissionais e a Coordenadora em Saúde Bucal do 
município, sendo que 05 enfermeiras não puderam comparecer.

Os cirurgiões-dentistas e as enfermeiras de cada USF reuniram-se, discutiram e relacionaram a implantação ou não das propostas anteriormente pactuadas, mediante resposta ao questionário:

1- Houve unificação do prontuário do paciente?

2- Cirurgião-dentista $(\mathrm{CD})$ realizou educação continuada durante as reuniões de equipe entre agosto e novembro/2012?

3- CD realizou capacitação em saúde bucal dos ACS?

4- A Equipe de Saúde Bucal (ESB) participou de grupos na USF entre agosto e novembro de 2012? Especifique.

5 - Houve agendamento de consulta odontológica para a gestante na abertura do SIS/pré-natal?

6- Houve parcerias entre ESB/escolas/creches para atendimento das crianças após autorização do responsável?

7- Houve promoção de atividades lúdicas para pacientes temerosos ao tratamento odontológico? Especifique.

8- Houve promoção de atividades vinculadas com a realidade local? Quais?

9- Houve maior integração entre profissionais da USF com a ESB? De que forma?

10- Houve parcerias em rede? Quais?

11- Foi facilitado o acesso dos trabalhadores às consultas odontológicas? De que forma?

12- Quais as dificuldades encontradas para a execução das estratégias elaboradas na $1^{\text {a }}$ oficina?
Pelo período de 2 horas houve a apresentação, pelos profissionais, das respostas, as quais foram tabuladas em planilha do Excel pela pesquisadora e pela orientadora para melhor visualização dos resultados. Em seguida, a pesquisadora apresentou aos profissionais os dados percentuais de aumento ou diminuição de faltas de cada USF, juntamente com as estratégias implantadas em cada Unidade.

Após a discussão dos dados em plenária por cerca de 45 minutos, houve o encerramento da oficina com a elaboração, pelos participantes, da síntese da discussão.

Foram descritas as frequências absolutas (n), relativas (\%) e intervalos de 95\% de confiança (IC) para as questões respondidas pelos usuários.

\section{Resultados}

Em relação ao perfil dos usuários faltantes, os dados demonstraram predomínio do sexo feminino $(62,3 \%)$ e a maior porcentagem dos usuários com idade entre 19 e 40 anos (40,3\%). Além disso, $36,4 \%$ dos entrevistados trabalhavam e $28,3 \%$ estudavam. Apenas 12,2\% deles possuíam convênio odontológico e 14,8\% eram cuidadores (de crianças, idosos, acamados, impossibilitados, etc.).

A Tabela 1 demonstra os motivos alegados pelos usuários para as faltas no período de janeiro a dezembro de 2010.

Em relação aos cirurgiões-dentistas, 58,3\% eram mulheres, com faixa etária compreendida entre 26 e 53 anos, predominando as idades entre

Tabela 1. Motivos de faltas às consultas odontológicas segundo os usuários. Piracicaba, 2012.

\begin{tabular}{lrcc}
\hline \multicolumn{1}{c}{ Motivos de faltas } & n & $\%$ & IC95\% \\
\hline Consulta marcada em horário de trabalho & 108 & 28,05 & $23,6-32,5$ \\
Mudança de bairro ou cidade & 60 & 15,58 & $12,0-19,2$ \\
Falta de tratamento completo na rede & 60 & 15,58 & $12,0-19,2$ \\
Usuário dependente de acompanhante & 43 & 11,17 & $8,0-14,3$ \\
Doença no dia da consulta & 25 & 6,49 & $4,0-9,0$ \\
Outro compromisso no dia da consulta & 16 & 4,16 & $2,2-6,1$ \\
Medo do atendimento odontológico & 15 & 3,90 & $2,0-5,8$ \\
Usuário é cuidador (de crianças, idosos) & 15 & 3,90 & $2,0-5,8$ \\
Falta de interesse pelo tratamento & 13 & 3,38 & $1,6-5,2$ \\
Impossibilidade de tratar devido à gestação & 13 & 3,38 & $1,6-5,2$ \\
Insatisfação com o cirurgião dentista e/ou Unidade de Saúde da Família & 11 & 2,86 & $1,2-4,5$ \\
Consulta agendada em horário escolar & 5 & 1,30 & $-{ }^{*}$ \\
Paciente faleceu & 1 & 0,26 & N $^{*}$ \\
\hline
\end{tabular}

*Nota: Não é possível determinar o Intervalo de Confiança (IC) quando $\mathrm{n}<10$ 
31 a 40 anos (58,3\%). Metade dos entrevistados (50\%) tinha entre 6 e 10 anos de profissão, e 75\% deles possuíam cursos de pós-graduação; 91,7\% dos cirurgiões-dentistas seguiam o protocolo da Coordenação em Saúde Bucal do município quanto à conduta aplicada ao paciente em caso de faltas às consultas odontológicas.

Foi medida a percepção dos cirurgiões dentistas em relação aos motivos das faltas dos usuários, conforme demonstrado na Tabela 2. Dentre os motivos que, na percepção dos mesmos levavam os usuários a faltarem nas consultas estão: para $15,38 \%$, o horário de trabalho do usuário incompatível com horário das consultas. Igual proporção $(15,38 \%)$ entende que o motivo é a não valorização da saúde bucal pela população; 9,62\% entendem que o medo do tratamento odontológico é fator de absenteísmo e igual proporção $(9,62 \%)$ apontam desinteresse do pacien- te pela própria saúde e a de seus familiares. Para 7,69\% após alívio da dor, paciente não retorna à consulta; $5,77 \%$ têm a percepção de que o motivo é esquecimento do dia e/ou horário da consulta. Além desses motivos percebidos pelos profissionais, outros como mudança de bairro por parte do paciente, a constatação de que muitos usuários possuem problemas de saúde que os impossibilitam de comparecerem, bem como a percepção de falta de comprometimento do usuário com o tratamento, dentre outros, também foram relatados pelos profissionais em menor proporção.

A Tabela 3 demonstra as respectivas propostas e sua não implantação em cada Unidade de Saúde participante desse estudo.

Já na Tabela 4 observa-se o percentual de aumento ou diminuição de faltas dos usuários às consultas após a implantação das estratégias nas USF.

Tabela 2. Estratégias propostas pelos profissionais para redução das faltas dos usuários. Piracicaba, 2012.

\begin{tabular}{lrr}
\hline \multicolumn{1}{c}{ Estratégias } & $\mathbf{n}$ & $\%$ \\
\hline Palestras sobre importância da saúde bucal e tratamento odontológico & 9 & 26,48 \\
Orientação dos usuários sobre regras de marcação de consultas e faltas & 5 & 14,71 \\
Orientação dos Agentes Comunitários de Saúde sobre saúde bucal durante visitas domiciliares & 3 & 8,82 \\
Motivação ao tratamento odontológico pela equipe & 3 & 8,82 \\
Confirmação prévia das consultas agendadas & 3 & 8,82 \\
Punição mais rigorosa quanto às regras para perda de vagas & 3 \\
Realização de atividades fora do consultório ou da USF & 8,82 \\
Realização de agendamento mais freqüente & 5,88 \\
Consentimento assinado pelo usuário comprometendo-se ao tratamento & 2 \\
Execução de trabalho comunitário pelo paciente faltoso & 2 \\
Primeira consulta e anamnese bem feitas dando confiança ao paciente & 1 & 2,98 \\
\end{tabular}

Tabela 3. Estratégias propostas não implantadas nas Unidades de Saúde da Família (USF). Piracicaba, 2012.

\begin{tabular}{|c|c|c|c|c|c|c|c|c|c|c|c|c|}
\hline \multirow[b]{2}{*}{ Estratégias } & \multicolumn{12}{|c|}{ USF } \\
\hline & A & B & $\mathrm{C}$ & $\mathbf{D}$ & $\mathbf{E}$ & $\mathbf{F}$ & G & $\mathbf{H}$ & I & $\mathbf{J}$ & $\mathbf{K}$ & $\mathbf{L}$ \\
\hline Prontuário único & $\mathrm{X}$ & - & $\mathrm{X}$ & - & $\mathrm{X}$ & $\mathrm{X}$ & $\mathrm{X}$ & $\mathrm{X}$ & - & - & - & $\mathrm{X}$ \\
\hline Educação continuada em saúde bucal & $\mathrm{X}$ & - & - & - & - & - & - & - & - & - & - & - \\
\hline Capacitação ACS em saúde bucal & - & - & - & - & $\mathrm{X}$ & - & - & - & $\mathrm{X}$ & - & $\mathrm{X}$ & - \\
\hline Participação ESB em grupos & - & - & - & - & - & - & - & - & - & - & - & - \\
\hline Atendimento às gestantes no pré-natal & - & - & - & - & - & $\mathrm{X}$ & - & - & - & - & - & - \\
\hline Parcerias para tratamento de crianças & - & - & - & - & - & - & $\mathrm{X}$ & - & - & - & - & - \\
\hline Atividades lúdicas à pacientes temerosos & - & - & - & - & - & - & $\mathrm{X}$ & - & $\mathrm{X}$ & $\mathrm{X}$ & $\mathrm{X}$ & $\mathrm{X}$ \\
\hline Atividades vinculadas à realidade local & - & - & - & - & - & - & - & - & - & - & - & $\mathrm{X}$ \\
\hline Maior integração com equipe & - & - & - & - & - & - & - & - & - & - & - & - \\
\hline Parcerias em rede & - & - & - & - & - & - & - & - & - & - & - & - \\
\hline Facilitar acesso ao trabalhador & - & - & - & - & - & - & - & - & $\mathrm{X}$ & - & - & - \\
\hline
\end{tabular}

$\mathrm{X}=$ não implantou prontuário único. 
Foram, ainda, investigadas as principais dificuldades das USF para implantação das estratégias propostas, conforme demonstra o Quadro 1.

Ao término da realização da segunda oficina de pesquisa-ação, foi elaborada uma síntese, pro- duzida após ampla discussão nos grupos e intergrupos, a qual apontou algumas conclusões sobre as ações propostas:

1) O prontuário único não é fator decisivo na questão de diminuição das faltas, mas pode ser um

Tabela 4. Número de consultas e faltas em 2010 e 2012 e percentual de aumento ou diminuição das mesmas após a implantação das estratégias nas Unidades de Saúde da Família. Piracicaba, 2012.

\begin{tabular}{lcccrr}
\hline $\begin{array}{c}\text { Unidade de Saúde } \\
\text { da Família }\end{array}$ & $\begin{array}{c}\text { consultas } \\
\mathbf{2 0 1 0}\end{array}$ & $\begin{array}{c}\text { faltas } \\
\mathbf{2 0 1 0}\end{array}$ & $\begin{array}{c}\text { consultas } \\
\mathbf{2 0 1 2}\end{array}$ & $\begin{array}{c}\text { faltas } \\
\mathbf{2 0 1 2}\end{array}$ & $\begin{array}{c}\text { \% } \\
\text { faltas }\end{array}$ \\
\hline A & 1.532 & 371 & 1.513 & 456 & $6 \%$ \\
B & 1.542 & 200 & 1.499 & 159 & $-2 \%$ \\
C & 1.201 & 262 & 1.019 & 171 & $-5 \%$ \\
D & 2.002 & 326 & 2.488 & 705 & $12 \%$ \\
E & 1.797 & 458 & 1.551 & 369 & $-2 \%$ \\
F & 2.120 & 154 & 1.346 & 354 & $19 \%$ \\
G & 1.326 & 458 & 1.332 & 381 & $-6 \%$ \\
H & 1.385 & 346 & 1.387 & 297 & $-4 \%$ \\
I & 1.906 & 508 & 1.177 & 222 & $-8 \%$ \\
J & 1.557 & 299 & 1.020 & 165 & $-3 \%$ \\
K & 2.137 & 404 & 1.972 & 690 & $16 \%$ \\
L & 1.570 & 134 & 1.336 & 93 & $-2 \%$ \\
\hline
\end{tabular}

Quadro 1. Dificuldades encontradas nas Unidades de Saúde da Família (USF) para implantação das propostas. Piracicaba, 2012.

\begin{tabular}{|c|l|}
\hline USF & \multicolumn{1}{|c|}{ Dificuldades } \\
\hline A & Fator cultural devido à falta de valorização da saúde bucal pela população. \\
\hline B & A utilização de prontuário único gerou adaptação de toda equipe técnica. \\
\hline C & Utilização de prontuário único, pois o cirurgião dentista (CD) atende 2 USF em único local. \\
\hline D & As parcerias em rede (escolas e creche) foram complicadas para toda a equipe. \\
\hline E & CD está há pouco tempo na Unidade, faltou tempo de integração com a equipe. \\
\hline F & $\begin{array}{l}\text { Utilização de prontuário único, pois CD atende 2 USF; falta de Comissão Local de Saúde (CLS) no } \\
\text { bairro. }\end{array}$ \\
\hline G & Utilização de prontuário único pela Equipe de Saúde Bucal. \\
\hline H & ACS resistentes em separar prontuários e receber capacitação; sem CLS no bairro. \\
\hline I & Equipe não aceitou a utilização de prontuário único. \\
\hline J & $\begin{array}{l}\text { Agentes Comunitários de Saúde (ACS) resistentes em separar prontuários para atendimento; sem } \\
\text { CLS no bairro. }\end{array}$ \\
\hline K & USF com equipe incompleta, o que dificultou a implantação de algumas estratégias. \\
\hline L & CLS criada muito recentemente, faltou tempo hábil para parcerias. \\
\hline
\end{tabular}


indutor de aumento de vínculo entre profissionais e usuários.

2) O prontuário único serve também como motivação para o CD conhecer melhor o histórico do paciente e assim obter maiores informações sobre sua saúde, oferecendo mais segurança a ambos durante o atendimento odontológico.

3) A participação do cirurgião-dentista em grupos na USF ajuda a mudar a "cultura" dos usuários e aumenta a valorização do trabalho do profissional perante a comunidade.

4) A realização de Educação Continuada pelo profissional aumenta a valorização do mesmo diante da equipe e por consequência, perante a população, além de lhe exigir maior preparo, pois uma equipe bem informada requer mais conhecimentos.

\section{Discussão}

A amostra do presente estudo foi composta, em sua maioria, por pessoas do gênero feminino. Segundo Baldani et al. ${ }^{16}$, vários estudos realizados no Brasil e em outros países buscaram explicar os determinantes individuais da utilização dos serviços odontológicos e constataram que mulheres, indivíduos mais jovens, com maior renda e escolaridade tendem a utilizar os serviços com maior frequência e/ou utilizá-los com maior regularidade. Isso, inclusive, poderia sugerir para os serviços a utilização das mulheres como multiplicadoras de conhecimentos em saúde (bucal e geral) e motivá-las à participação de grupos nas USF.

O funcionamento das USF em horário similar ao horário de trabalho da maioria dos usuários provavelmente explique o fato de ser este o maior motivo de faltas às consultas, tanto citado por usuários quanto na percepção dos dentistas. De acordo com Fonseca ${ }^{17}$, a elevada procura pelo pronto atendimento por indivíduos na idade adulta poderia ser explicada pelo não acolhimento nas Unidades Básicas de Saúde, quer pela falta de equipes de saúde bucal ou pela limitação de horário, ou ainda, pela tentativa de "entrada" no serviço por outra "porta", corroborando o documento da Política Nacional de Saúde Bucal de $2004^{18}$, que afirma que os adultos, em especial os trabalhadores, têm dificuldades no acesso às unidades de saúde nos horários de trabalho convencionais destes serviços. Ainda segundo o estudo, $19 \%$ das consultas do pronto atendimento nos dias úteis ocorreram no período noturno.

Durante a $1^{\text {a }}$ oficina de pesquisa-ação, os profissionais apontaram estratégias para ampliar o acesso dos trabalhadores às consultas. Isso corrobora a percepção de incompatibilidade de horários entre a rotina das pessoas e as USF, induzindo à reflexão: De que maneira essa dificuldade impacta na principal "vocação" da Estratégia de Saúde da Família - e da atenção primária em geral-que é a de ser a "porta de entrada" do sistema de saúde?

Ainda em relação ao acesso dos usuários aos serviços, considerando-se que a grande maioria da população entrevistada é "SUS - dependente", esperava-se que a utilização dos serviços de saúde bucal fosse maior.

Contudo, os resultados do presente estudo apontam para um contingente significativo desses usuários que faltaram às consultas em razão da inexistência de oferta de certos procedimentos na rede, o que impossibilita a conclusão clínica do tratamento. Segundo Almeida et al. ${ }^{19}$, a prestação de serviços de saúde bucal no Brasil, historicamente, tem se caracterizado pela oferta de ações de baixa complexidade, em sua maioria curativa e mutiladora, com acesso restrito. Neste sentido, durante a $1^{\text {a }}$ oficina de pesquisa-ação, aos gestores foi sugerida a necessidade de aumento da oferta de procedimentos odontológicos de maior complexidade na rede, como próteses parciais e unitárias, endodontia de molares sem restrição por idade e ortodontia preventiva.

Outro aspecto debatido nas oficinas foi que o acesso dos usuários ao serviço deve ocorrer de maneira acolhedora. $\mathrm{O}$ acolhimento é uma ação tecnoassistencial que pressupõe a mudança da relação profissional/usuário. Implica prestar um atendimento com resolutividade e responsabilidade, orientando adequadamente o paciente e a família quando necessário ${ }^{20}$. Nesse contexto, o diálogo com o usuário acerca de sua rotina diária antes do agendamento da consulta odontológica certamente reduziria as faltas às consultas, assim como a confirmação prévia das mesmas pela equipe de saúde bucal, conforme sugerido pelos próprios cirurgiões-dentistas.

A realização de palestras sobre a importância da saúde bucal e do tratamento odontológico foi estratégia proposta para enfrentamento do absenteísmo, já que, na opinião dos profissionais a não valorização da saúde bucal pela população traduz-se num dos os maiores motivos das faltas.

Interessante ressaltar que os $\mathrm{CD}$ focaram muito no caráter punitivo das sugestões quanto às faltas, o que demonstra ênfase do profissional em abordagens tradicionais, cujo foco é muito mais o resultado do que o processo em si. E, sobretudo, revela o tradicionalismo implícito nas 
práticas de promoção à saúde, cujas abordagens de culpabilização das vítimas, desconsideram contextos de vida, trazendo à tona a debilidade do modelo explicativo da promoção à saúde com a incorporação residual de fatores como classe, gênero e raça e a excessiva ênfase em intervenções behavioristas $^{21}$.

$\mathrm{E}$, nesse caso, os resultados induzem à questão: "Por que, então, não focar na motivação e no empoderamento dos usuários?"

O dentista que trabalha na Estratégia de Saúde da Família depara-se, frequentemente, com muitos desafios; e um deles - talvez um dos mais árduos - é empoderar o usuário, inserindo-o como parte integrante do cuidado a sua saúde. Para Fracolli e Zobolli22 ${ }^{22}$, projetos de promoção de saúde exitosos requerem ações intersetoriais que envolvam os indivíduos, suas famílias e a comunidade, utilizando recursos didático-pedagógicos facilitadores de aprendizagem, que auxiliem o diálogo entre profissionais e famílias. Segundo $\operatorname{Dias}^{23}$, no empoderamento deve haver participação, conscientização e sensibilidade das pessoas envolvidas neste processo, organizando a responsabilização entre quem conduz e quem recebe as informações e conhecimentos, ficando mais fácil a concretização da tomada de decisão pela família em realizar a ação efetiva de promoção e proteção da saúde bucal, com ênfase no autocuidado. Nesta lógica, o empoderamento aumenta a perspectiva no controle das ações que atingirão a saúde e a vida das pessoas.

Esposti et al. ${ }^{24}$ comentaram sobre a dificuldade de inserção dos cirurgiões-dentistas em equipes multiprofissionais, além da falta de integração às atividades desenvolvidas pelas equipes de Saúde da Família. Em um estudo desenvolvido por Maciel et al. ${ }^{25}$ sobre a interação com outros profissionais da equipe, $100 \%$ dos CDs responderam interagir com médicos e enfermeiros; o que chamou a atenção foi a fraca interação com agentes comunitários de saúde $(23,5 \%)$ que, na verdade, são aqueles que fazem o elo entre as famílias e os serviços de saúde.

Neste sentido, algumas estratégias implantadas nas USF após a $1^{\text {a }}$ oficina de pesquisa-ação demonstraram-se potencialmente eficazes para a valorização da saúde bucal na equipe. Dentre elas, a realização de educação continuada durante as reuniões de equipe, com a participação do CD expondo temas de saúde bucal, o que, inclusive, exige maior preparo do profissional. Segundo $\mathrm{Fa}$ $\mathrm{rah}^{26}$, a educação continuada complementa a formação dos profissionais, aproximando-os da realidade social e oferecendo subsídios para atender às necessidades de saúde da população, visando ao desenvolvimento pessoal e institucional. Ainda de acordo com Araújo e Dimenstein ${ }^{27}$, para que a educação em saúde se torne efetiva, é preciso que não só os profissionais da Odontologia participem desse processo, sendo fundamental o relacionamento com os demais membros da equipe. Um espaço valioso para esta prática é a reunião de equipe, onde o profissional pode refletir coletivamente certos conceitos, práticas e conhecimentos.

A capacitação em saúde bucal dos agentes comunitários de saúde pelo cirurgião-dentista também deve ser considerada com ênfase, visto que um dos participantes da oficina relatou a redução do uso inadequado do horário reservado para urgências nos serviços. Segundo o relato, isso ocorreu devido à maior conscientização dos usuários pelos ACS já que, naquela região, os ACS, após serem capacitados, levavam aos usuários, durante as visitas domiciliares, relevantes conhecimentos sobre saúde bucal e sobre o funcionamento dos serviços.

Percebe-se, portanto, que a capacitação e o empoderamento dos agentes comunitários em relação aos assuntos de saúde bucal, refletem-se na maior autonomia dos usuários, que além de melhor informados sobre o funcionamento da Unidade de Saúde, adquirem novos significados sobre o serviço, e, consequentemente passam a fazer uso adequado do mesmo.

Para Mialhe et al. ${ }^{28}$, quando os agentes estão capacitados a exercerem as práticas educativas em saúde bucal, pode haver o aumento da consciência da população para o autocuidado em saúde bucal. Ainda segundo David ${ }^{29}$, há um reconhecimento amplo da educação em saúde como uma das atribuições dos ACS.

Outra estratégia sugerida na $1^{\text {a }}$ oficina foi a participação dos profissionais nos grupos terapêuticos da USF (grupos de gestantes, hipertensos, diabéticos, puericultura, etc.). Tal medida parece ter potência, tanto para fortalecer a importância e o significado da saúde bucal junto a equipe, quanto para estreitar o vínculo dos profissionais da ESB com o restante da equipe e, sobretudo, com a comunidade. Nesse sentido, o agendamento de consulta odontológica para as gestantes já na abertura do SIS/Pré-natal também demonstra ser favorável, já que essas pacientes usualmente carregam consigo alguns mitos sobre inconveniência do tratamento odontológico durante a gravidez. Além disso, a oportunidade de tal marcação está também na otimização do tempo, já que dessa forma, inicia-se o tratamento logo no começo do período de gestação. 
Outra maneira de aumentar vínculo e acolhimento com a comunidade encontra-se nas parcerias entre equipe de saúde bucal e os equipamentos sociais do território, como escolas, creches, pastorais da criança, centros comunitários, igrejas, centros de assistência social etc., caminhando, assim, na direção da intersetorialidade, essencial para a promoção da saúde.

Em algumas USF deste estudo, a inexistência de comissão local de saúde (CLS) na área adstrita da unidade foi apontada como uma grande dificuldade, pois a comunidade não conseguia se organizar e fazer suas reivindicações, atrapalhando o relacionamento entre a equipe e a população. Segundo Lima et al. ${ }^{30}$, sendo a participação popular tão essencial à democracia moderna, deve-se considerar que espaços participativos efetivos requerem sujeitos educados para a cidadania e essa educação surge do exercício na própria prática democrática onde essa relação possa ser construída. Em relação a isso, sugere-se que o próprio profissional lance, nessas USF a discussão sobre a importância da criação desses espaços.

Algumas estratégias sugeridas desde a $1^{\text {a }}$ oficina não foram implantadas por dificuldades locais das equipes. A não utilização de prontuário único pareceu ser a medida mais desafiadora de todas para a maioria dos profissionais. Dentre os obstáculos elencados pelos entrevistados para tal unificação estão: o atendimento de usuários de duas áreas diferentes numa mesma Unidade de Saúde (pelo mesmo profissional) e falta de profissionais nas equipes, gerando dificuldades para a separação prévia dos prontuários para o atendimento.

Entretanto, ao término da $2^{\text {a }}$ oficina, a síntese elaborada após discussão em plenária resultou em consenso de que a adoção do prontuário único não é fator decisivo na questão de diminuição das faltas, mas pode ser um indutor de aumento de vínculo com o usuário, que sentiria mais confiança no profissional que estivesse devidamente informado sobre sua saúde e, portanto integralmente envolvido.

Outra grande vantagem da adoção do prontuário, segundo a síntese da $2^{\text {a }}$ oficina foi o fato de que as Unidades que a fizeram, perceberam maior facilidade na discussão de casos clínicos com a equipe, aumentando o vínculo e a integração entre seus membros. Além do mais, nos casos de transferência do usuário para outra USF, os registros de saúde bucal do mesmo estariam preservados e devidamente encaminhados para a nova Unidade de destino. Segundo Oliveira et al. ${ }^{31}$ o prontuário é essencial para acompanhar a evolução do paciente, como instrumento de educação permanente e de pesquisas clínicas e epidemiológicas, além de ser, potencialmente, instrução para atestar a qualidade do atendimento frente a questionamentos. No entanto, sua função primordial, como fonte de dados, vem sendo persistentemente prejudicada pela insuficiente qualidade de grande parte de seus registros.

Outra dificuldade encontrada pelas equipes foi relacionada ao manejo de pacientes com medo do tratamento. Para Meira Filho et al. ${ }^{32}$, o tratamento odontológico é uma experiência que envolve medo, ansiedade e estresse para a maioria das pessoas, sendo causa significativa de absenteísmo odontológico na adolescência e fase adulta. Estudos de Bailey et al., citados por Costa e Possobon ${ }^{33}$ mostraram que pacientes com baixa adesão ao tratamento são mais ansiosos quando comparados aos que apresentam alta adesão. Parece, assim, que a ansiedade do paciente o leva a esquivar-se do tratamento e também a não realizar práticas domésticas de manutenção da saúde bucal. Contudo, observou-se, pelos relatos dos profissionais, que os mesmos têm dificuldade em elaborar e conduzir ações e atividades que sejam úteis para enfrentar esse desafio, no caso atividades lúdicas. Tal dificuldade, provavelmente seja originada por modelos de formação mais tecnicista, adotados por parte das Instituições de Ensino Superior. Entende-se, todavia, que a reflexão sobre a importância desse enfrentamento, bem como sobre as questões relacionadas à humanização do atendimento é fundamental e deve ocorrer permanente e sistematicamente nas equipes, a fim de que se possa não somente superar limitações formativas dos profissionais, mas, sobretudo, qualificar a atenção à saúde dos usuários.

Verificou-se que das 12 USF participantes da amostra, 8 delas $(66,6 \%)$ obtiveram sucesso na abordagem sugerida. Todavia, dentre as 4 Unidades que não observaram redução no número de faltas, 3 tiveram a composição de suas equipes de saúde bucal modificada durante a realização deste estudo, dificultando desta forma a adesão às estratégias implantadas. E a outra USF (Jaraguá I) foi a única sem representatividade na primeira oficina, refletindo assim a importância da motivação alcançada com a participação nas oficinas de pesquisa-ação.

Embora este estudo forneça informações importantes sobre os motivos das faltas dos usuários às consultas e estratégias para redução das mesmas através da pesquisa-ação, não se pode deixar de considerar suas limitações. Na primeira cole- 
ta de dados sobre as faltas em 2010, não houve controle informatizado das mesmas; e em 2012, durante a segunda coleta, as faltas já eram inseridas em um sistema de informação. Assim, houve dois tipos de coleta de dados, com sistematização diferente, impossibilitando a verificação de significância no aumento ou na diminuição das faltas. Outra dificuldade encontrada, implícita ao trabalho, foi o contato telefônico com os usuários que faltaram às consultas em 2010, por terem mudado o número de telefone neste período.

Assim, preconiza-se a continuidade das oficinas de pesquisa-ação, para permanente avaliação das estratégias implantadas nas USF e também para a motivação constante dos profissionais.

\section{Conclusão}

As estratégias implementadas nas USF após as oficinas de pesquisa-ação levaram à diminuição das faltas às consultas odontológicas em $66,6 \%$

\section{Colaboradores}

CA Gonçalves, KL Cortellazzi, LM Guerra, FL Vazquez e AC Pereira participaram da concepção, do delineamento e da coleta dos dados. KL Cortellazzi, LM Guerra, FL Vazquez, KLM Sarracini, FL Mialhe e AC Pereira participaram da redação do artigo e/ou revisão crítica. As autoras GMB Ambrosano e KL Cortellazzi contribuíram na análise dos dados. das Unidades, pois houve interesse coletivo dos profissionais para a resolução do problema.

O caráter motivador das oficinas de pesquisa -ação possibilitou a reflexão crítica da realidade pelos participantes, para o redirecionamento da prática em saúde, o que se evidenciou na adoção, por parte de todas as Unidades de Saúde participantes, de $80 \%$ ou mais das ações propostas; sendo que, inclusive, duas delas adotaram todas as ações.

A metodologia da pesquisa-ação demonstrou potencial para o enfrentamento de desafios na atenção em saúde - dentre os quais o absenteísmo -, já que aliou o conhecimento e a reflexão da realidade local com a possibilidade de construção das mudanças necessárias por parte dos atores envolvidos. E, sobretudo, porque tal construção se deu de forma democrática e participativa, o que favoreceu a autonomia e o empoderamento dos trabalhadores envolvidos, revelando um processo de trabalho com potencial transformador e produtor de sujeitos, de saúde e de mudanças.

\section{Referências}

1. Gil CRR. Formação de recursos humanos em saúde da família: paradoxos e perspectivas. Cad Saude Publica 2005; 21(2):490-498.

2. Brasil. Ministério da Saúde (MS). Secretaria de Atenção à Saúde. Departamento de Atenção Básica, Estratégia de Saúde da Família. Brasília: MS; 2013 [acesso 2013 abr 16]. Disponível em: http://www.dab.saude.gov.br/ portaldab/ape_esf.php.

3. Pinheiro PM, Oliveira LC. A contribuição do acolhimento e do vínculo na humanização da prática do cirurgião-dentista no Programa Saúde da Família. Interface (Botucatu) 2011; 15(36):185-198.

4. Munkeviz MSG, Pelicioni MCF. Saúde Bucal na Estratégia Saúde da Família no município de São Paulo: perspectiva do usuário. Rev Bras Cres Desenvolv Hum 2010; 20(3):787-797.

5. Jandrey CM, Drehmer TM. Absenteísmo no atendimento clínico odontológico: o caso do módulo de serviço comunitário do Centro de Pesquisas em Odontologia Social - UFRGS. Rev. Fac. Odontol. 1999; 40(1):24-28.

6. Bender AS, Molina LR, Mello ALSF. Absenteísmo na atenção secundária e suas implicações na atenção básica. Revista Espaço para a Saúde 2010; 11(2):56-65. 
7. Almeida GL, Garcia LFR, Almeida TL, Bittar TO, Pereira AC. Estudo do perfil socioeconômico dos pacientes e os motivos que os levaram a faltar em consultas odontológicas na estratégia de saúde da família em uma distrital de Ribeirão Preto/SP. Cien Odontol Bras 2009; 12(1):77-86

8. Cohen LK. Converting unmet need for care to effective demand. Int Dent J 1987; 37(2):114-116.

9. Costa GD, Cotta RMM, Ferreira MLSM, Reis JR, Franceschini SCC. Saúde da família: desafios no processo de reorientação do modelo assistencial. Rev Bras Enferm. 2009; 62(1):113-118

10. Merhy EE. O ato de cuidar: a alma dos serviços de saúde. In: Brasil. Ministério da Saúde (MS). Secretaria de Gestão do Trabalho e da Educação na Saúde. Departamento de gestão da Educação na Saúde. Rev - SUS Brasil: cadernos de textos. Brasília: MS; 2004. Série B textos básicos de saúde. p. 108-137.

11. Nascimento MAA, Mishima SM. Construindo uma prática de relações. Jor. Assoc. Bras. Enferm. 2004; 2(2) $12-15$

12. Camargo-Borges C, Japur M. Sobre a (não) adesão ao tratamento: ampliando sentidos do autocuidado. Texto \& Contexto Enferm. 2008; 17(1):64-71.

13. Robles ACC, Grosseman S, Bosco VL. Satisfação com o atendimento odontológico: estudo qualitativo com mães de crianças atendidas na Universidade Federa de Santa Catarina. Cien Saude Colet 2008; 13(1):43-49.

14. Franco MAS. Pedagogia da pesquisa-ação. Educ. Pesqui. 2005; 31(3):483-502.

15. Adelman C. Kurt Lewin and the origins of action research. Educational Action Research 1993; 1(1).

16. Baldani $\mathrm{MH}$, Brito WH, Lawder JAC, Mendes YBE Silva FFM, Antunes JLF. Determinantes individuais da utilização de serviços odontológicos por adultos e idosos de baixa renda. Rev Bras Epidemiol 2010; 13(1):150 162

17. Fonseca DAV. A influência sociodemográfica e da organização do serviço, na procura pelo pronto atendimento odontológico no município de Piracicaba [dissertação] Piracicaba: UNICAMP/FOP; 2011.

18. Brasil. Ministério da Saúde (MS). Secretaria de Atenção à Saúde. Departamento de Atenção Básica, Estratégia de Saúde da Família. Brasília; 2013 [acessado 2013 abr 16]. Disponível em: http://www.dab.saude.gov.br/portaldab/ape_esf.php

19. Almeida GL, Garcia LFR, Almeida TL, Bittar TO, Pereira AC. Estudo do perfil socioeconômico dos pacientes e os motivos que os levaram a faltar em consultas odontológicas na estratégia de saúde da família em uma distrital de Ribeirão Preto/SP. Cien Odontol Bras 2009; 12(1):77-86

20. Falk MLR, Falk, JW, Oliveira, FA, Motta, MS. Acolhimento como dispositivo de humanização: percepção do usuário e do trabalhador em saúde. Rev APS 2010 13(1):4-9.
21. Carvalho DQ, Ely HC, Paviani LS, Corrêa PEB. A dinâmica da equipe de saúde bucal no Programa Saúde da Família. Bol. saúde 2004; 18(1).

22. Fracolli LA, Zoboli ELCP. A promoção da saúde como uma competência do ACS: em foco a construção da autonomia. In: Pelicioni, MCF, Mialhe, FL, organizadores Educação e promoção da saúde: teoria e prática. São Paulo: Santos; 2012. p. 513-522.

23. Dias CR. Promoção e proteção da saúde bucal na família: o cotidiano da prevenção. São Paulo: Santos; 2012.

24. Esposti CDD, Oliveira AE, Silva MZ, Lima RCD. Perspectivas da saúde bucal na Estratégia Saúde da Família: dificuldades e avanços. UFES Rev Odontol 2007; 8(3):49-54.

25. Maciel CF, Barcellos LA, Miotto MHMB. Perfil dos cirurgiões-dentistas do Programa de Saúde da Família da Grande Vitória - parte II. UFES Rev Odontol 2007 9(1):20-25.

26. Farah BF. Educação em serviço, educação continuada educação permanente em saúde: sinônimos ou diferentes concepções? Rev APS 2003; 6(2):123-125.

27. Araújo YP, Dimenstein M. Estrutura e organização do trabalho do cirurgião-dentista no PSF de municípios do Rio Grande do Norte. Cien Saude Colet 2006; 11(1):219-227

28. Mialhe FL, Lefrève F, Lefrève AMC. O agente comunitário de saúde e suas práticas educativas em saúde bucal: uma avaliação qualiquantitativa. Cien Saude Colet 2011; 16(11):4425-4432.

29. David HMSL. Educação em saúde e o trabalho dos agentes comunitários de saúde. In: Mialhe FL, organizador. O agente comunitário de saúde: práticas educa tivas. Campinas: Editora da Unicamp; 2011. p. 51-82.

30. Lima RA, Souza LL, Pereira EM, Queiroz MG. Conselhos locais de saúde: redescobrindo e ampliando espaços para a prática da odontologia. Rev Tempus Actas Saúde Coletiva 2009; 3(3):78-89.

31. Oliveira TML, Silva NAS, Oliveira GMM, Klein $\mathrm{CH}$ Qualidade da informação sobre cirurgia de revascularização do miocárdio em prontuários: o caso da abrangência - Rio de Janeiro, 1999 - 2003. Rev SOCERJ 2008; 21(6):372-381

32. Meira Filho MMO, Araújo DTC, Menezes VA, Garcia AFG. Atendimento odontológico da criança: percepção materna. RGO 2009; 57(3):311-315.

33. Costa LST, Possobon RF. Variáveis de desistência entre participantes de um programa de atenção precoce à saúde oral. Rev Odontol UNESP 2012; 41(1):22-26.

Artigo apresentado em 06/03/2014

Aprovado em 12/06/2014

Versão final apresentada em 14/06/2014 